\title{
Sudden cardiac death - a known unknown?
}

\author{
Jana Obrovaa ${ }^{a}$ Eliska Sovova ${ }^{b}$, Eva Kocianovaa ${ }^{a}$ Milos Taborsky ${ }^{a}$
}

Sudden cardiac death (SCD) is a major medical, economic and social problem. The estimated annual number of SCDs is approximately 4 million cases worldwide. Approximately $50 \%$ of SCDs are unexpected first manifestations of cardiac disease. The survival rate after out-of-hospital cardiac arrest is low even in countries with the most advanced health care systems. It all emphasizes the importance of prevention, in which implantable cardioverter-defibrillators play a dominant role. However, our ability to recognize high-risk patients remains insufficient. Moreover, a declining rate of shockable rhythm as the initial recording has been reported in the last decades. Despite numerous SCD studies and undisputed progress, there are still many unanswered questions.

Key words: sudden cardiac death, mechanism, prevention, risk stratification, implantable cardioverter-defibrillator

Received: July 9, 2021; Revised: October 18, 2021; Accepted: November 5, 2021; Available online: November 15, 2021 https://doi.org/10.5507/bp.2021.065

(c) 2022 The Authors; https://creativecommons.org/licenses/by/4.0/

aDepartment of Internal Medicine I - Cardiology, University Hospital Olomouc and Faculty of Medicine and Dentistry, Palacky University Olomouc, Czech Republic

${ }^{b}$ Department of Exercise Medicine and Cardiovascular Rehabilitation, University Hospital Olomouc and Faculty of Medicine and Dentistry, Palacky University Olomouc, Czech Republic

Corresponding author: Jana Obrova, e-mail: obrova.jana@gmail.com

\section{INTRODUCTION}

Sudden cardiac death $(\mathrm{SCD})$ is a natural death from cardiac causes, heralded by abrupt loss of consciousness within one hour of the onset of an acute change in cardiovascular status. If unwitnessed, subjects should have been observed alive within 24 hours of their death ${ }^{1}$. It represents a serious problem due to its incidence and impact on society, especially the victims' families. The burden of premature death is greater for SCD than for all individual cancers and most other leading causes of death ${ }^{2}$. The aims of this review article are to provide current insights into the causes, mechanism, preventive and management strategies and to point out the gaps in our knowledge.

\section{EPIDEMIOLOGY}

The worldwide incidence of SCD is difficult to estimate. Existing SCD registries are highly concentrated in Western Europe and North America, with low-income and middle-income regions of the world lacking surveillance of SCD $\left(\right.$ ref. $\left.^{3}\right)$. The annual numbers of SCD cases are derived from various sources and thus range widely, for example, from 184,000 to 462,000 in the United States ${ }^{1,4}$. Studies using retrospective death certificate-based methodology are likely to significantly overestimate SCD incidence $^{5}$. Autopsies are seldom performed and detailed clinical records are often unavailable. Data collected by first responders to primary cardiac arrest do not include the significant proportion of cases that are unwitnessed. Ambulance-reported data miss cases transported directly to coronial services. Although integrating multisource data seems to be the most suitable approach, comprehen- sive multisource surveillance registries or studies are few. The most cited data are those reported by the American Heart Association; its 2020 statistical update lists 379,133 SCDs per year in the United States $(114 / 100,000)\left(\right.$ ref. $\left.^{6}\right)$. The global annual incidence is calculated to be $100-200$ per 100,000 population. The estimated annual burden of SCD would be approximately 4 million cases worldwide.

The incidence has two peak ages. The first in infancy, often associated with complex congenital heart disease (73/100,000 person-years). In adolescents and adults under 30 years of age, the rate decreases to approximately $6 / 100,000$ person-years. From 35-45 years of age, the risk of SCD increases, with the second peak at around 75 years of age. Black people have a higher risk of SCD across all age groups. SCD has a large preponderance in men relative to women during the young adult and early middle-age years because of the protection that women enjoy from coronary atherosclerosis before menopause. Men have a fourfold to sevenfold greater incidence of SCD than women before 65 years of age, at which point the difference decreases to $2: 1$ or less and continues to decrease with advancing age ${ }^{1}$.

\section{ETIOLOGY}

SCD is associated with many causes and contributing factors (Table 1). Preexisting coronary artery disease and its consequences (acute myocardial ischemia, scarring from previous myocardial infarction, heart failure) are manifest in $80 \%$ of SCD victims. Dilated nonischemic and hypertrophic cardiomyopathies account for the second largest number of SCDs, whereas other cardiac disorders, including congenital heart defects and the known 
Table 1. SCD causes and contributing factors (adapted from Myerburg 2018 (ref. ${ }^{1}$ ))

\begin{tabular}{|c|c|}
\hline Coronary artery abnormalities & $\begin{array}{l}\text { atherosclerosis, congenital abnormalities, embolism, arteritis, mechanical } \\
\text { and functional obstruction }\end{array}$ \\
\hline Hypertrophy of the ventricular myocardium & $\begin{array}{l}\text { left ventricular hypertrophy associated with coronary heart disease, } \\
\text { hypertension, secondary to valvular heart disease }\end{array}$ \\
\hline $\begin{array}{l}\text { Myocardial diseases and dysfunction, with or } \\
\text { without heart failure }\end{array}$ & conditions leading to acute or chronic heart failure \\
\hline $\begin{array}{l}\text { Inflammatory, infiltrative, neoplastic and } \\
\text { degenerative processes }\end{array}$ & myocarditis, sarcoidosis, amyloidosis, tumors \\
\hline Diseases of the cardiac valves & $\begin{array}{l}\text { valvular aortic stenosis/insufficiency, mitral valve disruption, mitral valve } \\
\text { prolapse, endocarditis, prosthetic valve dysfunction }\end{array}$ \\
\hline Congenital heart disease & $\begin{array}{l}\text { congenital aortic or pulmonic valve stenosis, congenital septal defects } \\
\text { with Eisenmenger physiology }\end{array}$ \\
\hline Electrophysiologic abnormalities & $\begin{array}{l}\text { abnormalities of the conducting system, congenital/acquired } \\
\text { abnormalities in duration of the QT interval, Brugada syndrome, } \\
\text { ventricular fibrillation of unknown cause }\end{array}$ \\
\hline $\begin{array}{l}\text { Electrical instability related to neurohumoral and } \\
\text { central nervous system influences }\end{array}$ & $\begin{array}{l}\text { catecholaminergic polymorphic ventricular tachycardia, central nervous } \\
\text { system-related }\end{array}$ \\
\hline Miscellaneous & $\begin{array}{l}\text { sudden death during extreme physical activity, toxic and metabolic } \\
\text { disturbances, sudden infant death syndrome }\end{array}$ \\
\hline
\end{tabular}

genetically determined ion channel anomalies, account for $5-10 \%$ of SCDs (ref. ${ }^{1,7,8}$ ).

The spectrum of SCD causes varies with age. In the young, there is a predominance of channelopathies, cardiomyopathies and myocarditis; in older populations, chronic degenerative diseases (coronary artery disease, valvular heart diseases and heart failure) predominate. Cardiovascular mortality has decreased in recent decades due to primary and secondary prevention as well as advances in acute treatment. Despite this, cardiovascular diseases remain the leading cause of death in developed countries and approximately $50 \%$ of all these deaths are sudden and unexpected, occurring shortly after the onset of symptoms ${ }^{1}$. The presence of heart failure (HF) increases the incidence of SCD fourfold ${ }^{9}$. The annual mortality of people with $\mathrm{HF}$ with reduced ejection fraction (HFrEF) is around $15 \%$, about half of deaths being sudden. Severe left ventricular dysfunction with an ejection fraction below $35 \%$ is the most accurate and independent predictor of SCD. The overall mortality increases with worsening functional capacity, usually expressed using the New York Heart Association functional classification system (NYHA class I-IV). However, patients with HF and better functional capacity (NYHA class II) have a higher risk of dying suddenly than those with worse capacity (NYHA class IV) (ref. ${ }^{1}$ ).

\section{RISK FACTORS}

As most SCDs are due to coronary heart disease (CHD), it is not surprising that they have similar risk factors such as hypertension, diabetes mellitus, obesity, smoking and psychosocial factors. The association between physical activity and SCD is affected by the intensity and regularity of exercise. Vigorous exercise increases the risk of SCD, particularly in otherwise inactive people. However, regular exercise attenuates this risk ${ }^{10}$. A positive family history is a significant independent risk factor for SCD. Occurrence of SCD in first-degree relatives led to a 1.6- to 2.2-fold increase in SCD susceptibility after controlling for traditional risk factors of coronary artery disease ${ }^{11-13}$. Familial patterns of risk for SCD, which result from known or suspected genetic variations, are emerging as important factors for risk profiling. The various genetic associations can be separated into four categories: inherited uncommon primary arrhythmic syndromes (e.g. long QT syndromes (Fig. 1), Brugada syndrome (Fig. 2), catecholaminergic polymorphic ventricular tachycardia or fibrillation), inherited uncommon structural diseases associated with risk for SCD (e.g. hypertrophic cardiomyopathy, arrhythmogenic cardiomyopathy), "acquired" or induced risk for arrhythmias (e.g., drug-induced long QT interval or proarrhythmia, electrolyte disturbances) and common acquired diseases associated with risk for SCD (e.g. CHD, nonischemic cardiomyopathies) (ref. ${ }^{1}$ ). Several studies have suggested that SCD as the initial expression of CHD demonstrates familial clustering ${ }^{11,13}$.

\section{MECHANISM}

The propensity to die suddenly originates as a "perfect storm" - interaction of a vulnerable substrate (genetic or acquired changes in the electrical or mechanical properties of the heart) with multiple transient factors that participate in triggering the fatal event ${ }^{7}$. In the past, the most common (80-95\%) sequence of events leading to SCD was degeneration of ventricular tachycardia (VT) into ventricular fibrillation (VF), often followed by asystole or pulseless electrical activity (PEA) (ref. ${ }^{14-16}$ ). Nowadays, however, the most common initial documented recording 


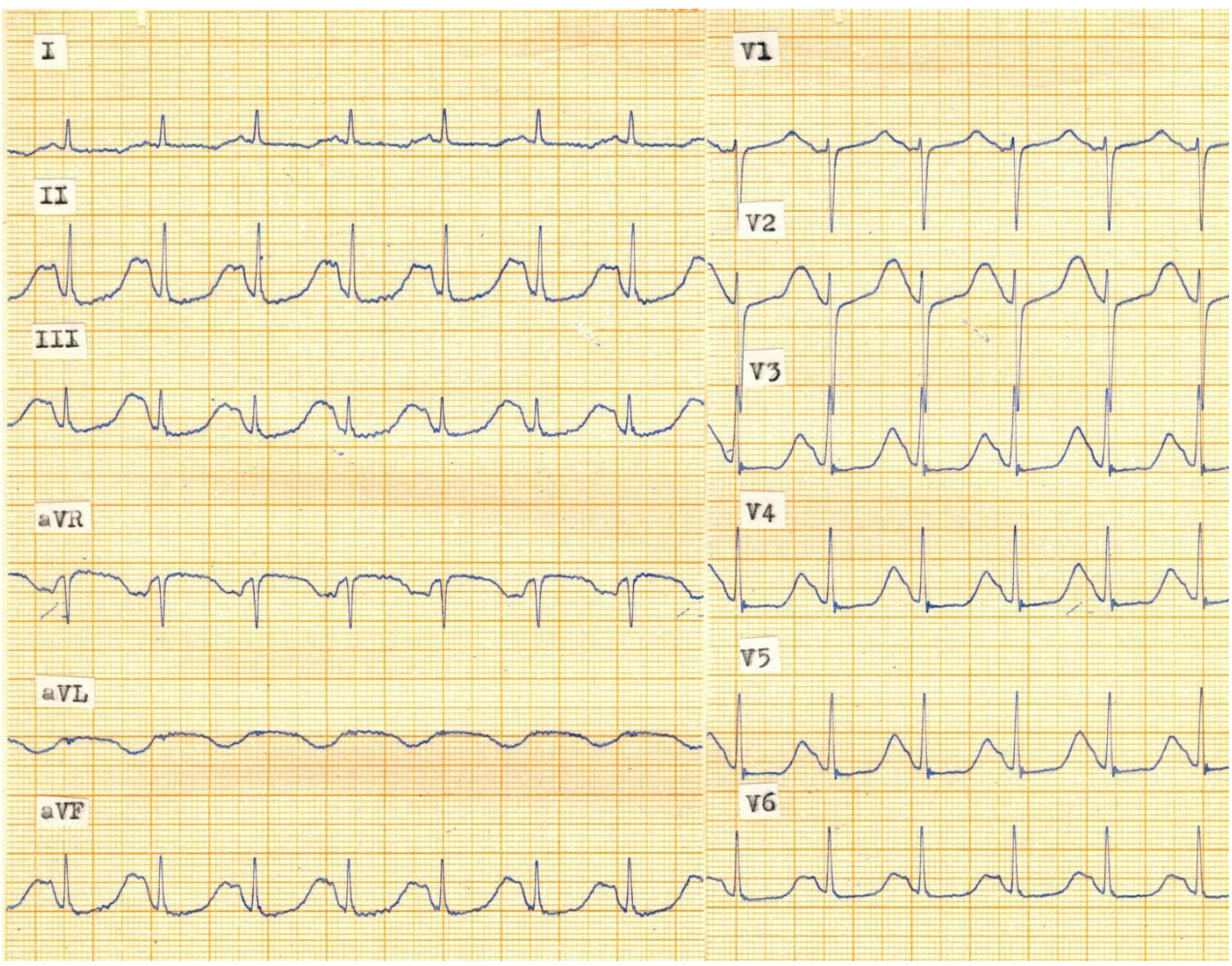

Fig. 1. Long QT syndrome (published with the permission of ass.professor Čestmír Čihalík).

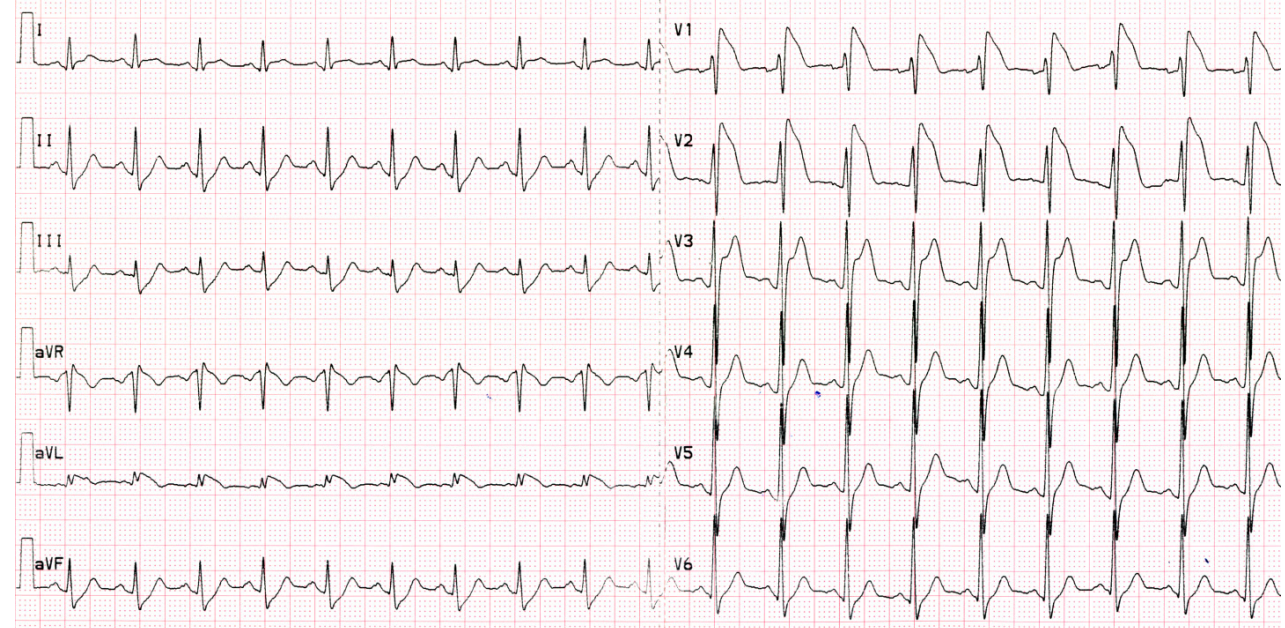

Fig. 2. Brugada syndrome (published with the permission of ass.professor Čestmír Čihalík).

is asystole or PEA. The first recorded rhythm certainly depends on the time from loss of consciousness to the recording of the electrocardiogram, with an increasing number of false-positive asystolic and bradyarrhythmic cases with time. But in the last three decades, a declining rate of VT/VF has been reported despite significant improvements in response time and rates of bystander cardiopulmonary resuscitation ${ }^{17-20}$. Kuisma et al. reported a $48 \%$ decrease in the incidence of out-of-hospital VF from 1994 to 1999 in Finland ${ }^{18}$. A study from Seattle, USA, recorded a $43 \%$ decline in the incidence of out-of-hospital VF from 1980 to 2000 (ref. ${ }^{19}$ ). The exact reasons have not been fully explained. It is probably related to better primary and secondary prevention of cardiovascular disease and to an aging population. Advanced age is associated with non-shockable rhythms during sudden cardiac arrest. The increased prevalence of end-stage heart failure patients may have influenced the rates of non-shockable cardiac arrest, as terminal heart failure is typically characterized by PEA/asystole ${ }^{21}$. It has a powerful impact on patient outcome and treatment. Patients with asystole or PEA at initial contact have worse prognosis. In a prospective multicenter observational study of 36,902 adults with in-hospital cardiac arrest, the prevalence of VF/VT as the first documented rhythm was $23 \%$, asystole $35 \%$ and PEA $32 \%$ and rates of survival to hospital discharge for first documented rhythms of VF/VT were $36 \%$, asystole $10.6 \%$ and PEA $11.2 \%$ (ref. $^{22}$ ). Similar results were found 
in another prospective study involving more than 50,000 patients $^{23}$. Research has focused mostly on SCD due to VF/VT. Therapeutic protocols focus on early defibrillation. Great efforts and investments have been made to equip strategic locations with automatic external defibrillators. However, this will not help if the initial rhythm is unshockable. SCD due to PEA and asystole is a challenge for the future.

\section{TREATMENT}

Continuous cardiopulmonary support and restoring spontaneous circulation as quickly as possible are the main principles in cardiac arrest management. In most communities, the median time from emergency call to emergency medical service arrival is 5-8 min, or 8-11 min to a first shock ${ }^{24}$. During this time, the victim's survival depends on bystanders. The immediate initiation of cardiopulmonary resuscitation (CPR) can double or triple survival from cardiac arrest. Defibrillation within 3-5 min of collapse can produce survival rates as high as $50-70 \%$. Each minute of delay to defibrillation reduces the probability of survival to discharge by $10-12 \%$ without CPR and by $3-4 \%$ with CPR (ref. ${ }^{25}$ ).

After 10 and more minutes without defibrillation, 95\% of people die. Even if CPR was started, only $8 \%$ of patients survived for at least 30 days after out-of-hospital cardiac arrest or to hospital discharge ${ }^{26}$.

After return of spontaneous or stable assisted circulation, focus shifts to the diagnostic and therapeutic elements of post-cardiac arrest syndrome, which include brain injury, myocardial dysfunction, systemic ischemia/ reperfusion responses and control of persistent precipitating factors ${ }^{1}$. Survivors should be admitted to an intensive care unit (cardiac arrest center if available). Management is determined by the specific cause and underlying pathophysiologic process. Finally, a long-term management strategy to prevent recurrent cardiac arrest has to be established according to the causation and patient functional status.

\section{PREVENTION}

We distinguish between primary and secondary prevention of SCD. Secondary prevention is intended for persons who have already overcome circulatory arrest or life-threatening arrhythmia. Primary prevention is for those who have a higher risk of SCD but have not yet overcome circulatory arrest or life-threatening arrhythmia. In both groups, the treatment is complex and includes pharmacological and non-pharmacological procedures. Effective therapy of underlying heart disease and associated comorbidities is fundamental. Then we can choose and combine various antiarrhythmic strategies (pharmacotherapy, cardioverter-defibrillator implantation, catheter ablation, surgical treatment). High expectations were set for pharmacological treatment. However, the results of studies with class 1 antiarrhythmics were disappoint- ing $^{27,28}$. Although these agents led to a decrease in premature ventricular contractions, the overall mortality of individuals increased. Amiodarone reduces the incidence of arrhythmic deaths without reduction of all-cause mortality $^{29,30}$ and it is not suitable for prophylactic use ${ }^{31}$. Only beta-blockers have shown a positive effect on the incidence of SCD and all-cause mortality. They reduce the risk of SCD by $32-55 \%$ (ref. ${ }^{32-34}$ ). They have prognostic significance for patients after acute myocardial infarction. Beta-blockers (bisoprolol, carvedilol, metoprolol succinate, nebivolol) have been shown to reduce mortality and morbidity in patients with HFrEF and should be commenced as soon as the diagnosis is established, once the patient is haemodynamically stabilized ${ }^{35}$. According to substantial consensus among experts the non-selective betablockers (nadolol) are the preferred effective drug therapy in long QT syndromes and catecholaminergic polymorphic ventricular tachycardia, and, whenever tolerated, it should be administered as a first-choice therapy ${ }^{36}$.

Angiotensin-converting enzyme inhibitors (ACEi), angiotensin II type I receptor blockers (ARB) and mineralocorticoid receptor blockers promote reverse myocardial remodeling and reduce the risk of SCD (ref. ${ }^{7}$ ). Administration of a dual antagonist of angiotensin II and neprilysin receptors (ARNI - angiotensin receptorneprilysin inhibitor) resulted in reduction of overall cardiovascular mortality and, more specifically, 20\% SCD risk reduction in HFrEF patients. ARNI has been associated with improvements in diastolic function, left ventricular function, quality of life and burden of ventricular arrhythmias ${ }^{37,38}$ Current guidelines recommends replacing ACEi or ARB with ARNI in ambulatory patients with HFrEF, who remain symptomatic despite optimal treatment. Initiation of ARNI in ACEi naive patients with HFrEF may be considered (class of recommendation IIb, level of evidence B) (ref. ${ }^{35}$ ). They also recommends a new class of drug - sodium-glucose cotransporter-2 inhibitors (SGLT2i) in patients with HFrEF. Among these patients, an SGLT2i has shown a reduced risk of worsening HF or death from cardiovascular causes regardless of the presence of diabetes ${ }^{35}$. It seems that SGLT2i are associated with significantly reduced risks of SCD in patients with type 2 diabetes mellitus ${ }^{39}$. Prospective trials are warranted to confirm the antiarrhythmic effect of SGLT2i.

Nowadays, implantable cardioverter-defibrillators (ICDs) play a dominant role in the prevention of SCD, reducing mortality by $23-55 \%$ compared to antiarrhythmic therapy ${ }^{31,40-44}$. For understandable medical and economic reasons, this method is intended only for people at high risk of SCD. However, risk stratification has been a big challenge.

\section{Implantable cardioverter-defibrillator}

The first ICDs were approved for implantation in the United States in 1985 and were indicated in survivors of cardiac arrest or life-threatening arrhythmia. Persons with documented VF or hemodynamically untolerated VT in the absence of reversible causes or within $48 \mathrm{~h}$ after myocardial infarction are still considered to be at high risk. Those receiving optimal chronic medical therapy and 
having a reasonable expectation of survival with a good functional status for more than one year undergo implantation of an ICD for secondary prevention ${ }^{7}$. However, they represent only a small percentage of those at risk for SCD. Most people die during their first episode of malignant arrhythmia, which emphasizes the importance of primary prevention. The current European Society of Cardiology recommends ICD implantation as primary prevention in the following cases ${ }^{7}$ :

\section{Left ventricular dysfunction}

The individual's left ventricular ejection fraction (LVEF) and functional capacity are central to SCD risk stratification. According to the guidelines, ICD therapy is recommended in patients with symptomatic HF (NYHA class II-III) regardless of etiology and LVEF $\leq 35 \%$ after more than 3 months of optimal medical therapy who are expected to survive for at least 1 year with good functional status.

\section{Coronary artery disease}

Up to $6 \%$ of patients with acute coronary syndrome develop VT or VF. However, early ICD implantation does not improve the prognosis and is not indicated ${ }^{45,46}$. It may be considered in the presence of specific conditions (preexisting LVEF dysfunction, incomplete revascularization, occurrence of arrhythmias more than 48 hours after the onset of acute coronary syndrome, polymorphic VT or VF). Assessment of LVEF is recommended in all patients with acute myocardial infarction before discharge and 6-12 weeks after myocardial infarction. The majority of patients with severely depressed LVEF immediately after myocardial infarction show significantly improved systolic function after 3 months. If left ventricular dysfunction persists, ICD implantation is recommended.

\section{Cardiomyopathies}

Besides left ventricular dysfunction, the guidelines recommend primary ICD prophylaxis in some patients with dilated, hypertrophic and arrhythmogenic right ventricular cardiomyopathy. Lamin A/C gene associated cardiomyopathy is a form of dilated cardiomyopathy with poor prognosis, a rapid evolution toward end-stage heart failure and malignant ventricular arrhythmias associated with increased risk of sudden cardiac death. Screening of first degree relatives is useful for the early diagnosis of the disease. ICD implantation should be considered in case of dilated cardiomyopathy with a confirmed diseasecausing mutations in lamin $\mathrm{A} / \mathrm{C}$ and at least two of these risk factors: non-sustained VT during ambulatory electrocardiogram monitoring, LVEF $<45 \%$ at first evaluation, male sex and non-missense mutations (insertion, deletion, truncations or mutations affecting splicing). The decision to implant an ICD to a patient with hypertrophic cardiomyopathy is based on the 5-year SCD risk calculated using the HCM Risk-SCD model and taking into account the age and general health of the patient. ICD implantation should be considered in patients with arrhythmogenic right ventricular cardiomyopathy and unexplained syncope or hemodynamically well-tolerated sustained VT. It may be considered in patients with one or more recognized risk factors for ventricular arrhythmia following detailed clinical assessment (frequent non-sustained VT, a family history of premature sudden death, extensive right ventricle disease, marked QRS prolongation, late gadolinium enhancement on cardiac magnetic resonance imaging, left ventricular dysfunction and VT induction during electrophysiological study).

\section{Inherited primary arrhythmia syndromes}

This is a diverse group of inherited syndromes with heterogeneous manifestations, from asymptomatic carriers to SCD. ICD implantation for secondary prevention is generally accepted. Primary prevention recommendations are based on expert opinion and small observational studies. The device implantation should be considered individually. According to the guidelines, it is recommended in patients with long QT syndrome (Fig. 1) who experienced syncope and/or VT while receiving an adequate dose of beta-blockers. It may be considered in high-risk patients such as women with LQT2 and corrected QT more than $500 \mathrm{~ms}$, patients with corrected QT more than $500 \mathrm{~ms}$ and signs of electrical instability and those with high-risk genetic profiles. It is also indicated in patients

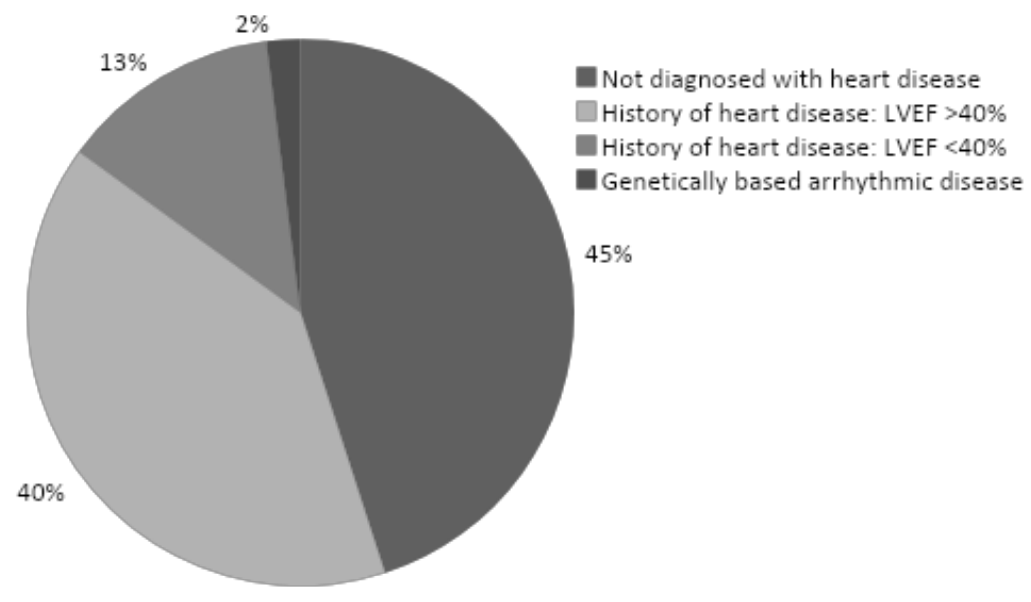

Fig. 3. The different groups that contribute to the total number of SCDs (adapted from Wellens $2014\left(\right.$ ref. $\left.^{47}\right)$ ). 
with Brugada syndrome (Fig. 2) with documented VT and in those presenting with a spontaneous type 1 electrocardiogram pattern and a history of syncope. Finally, ICD implantation is recommended in patients with catecholaminergic polymorphic VT and recurrent syncope or polymorphic/bidirectional VT despite optimal therapy (beta-blockers or flecainide).

\section{Limits of current risk stratification}

Secondary ICD prophylaxis is well defined, effective and generally accepted. The situation in primary prevention is more complicated. The current primary preventive strategies are targeted at a preselected population of people with certain characteristics of heart disease. However, only $55 \%$ of SCD victims had known heart disease at the time of death (Fig. 3) (ref. ${ }^{47}$ ). In almost half of the cases, cardiac arrest is the first symptom of cardiac disease. Our ability to identify individuals at risk for SCD in this group remains poor. It is the primary challenge of the "Myerburg paradox". As already mentioned, traditional risk factors increase the risk of SCD, but they cannot be used for SCD risk stratification. Traditional risk factors cannot distinguish people at increased risk for SCD from people with other manifestations of CHD. Cardiology examination would reveal some cases but it is not suitable for identifying possible candidates from the general population. Screening is recommended only for athletes who have a higher risk of arrhythmias and worsening of structural or genetic heart disease during intense physical exercise and for first-degree relatives of sudden death victims ${ }^{7}$. In this case, a comprehensive autopsy examination including macroscopic, histological and toxicology assessment and postmortem genetic testing of SCD victims can be helpful. Palpitations, presyncope and syncope are the three most important symptoms that require taking a thorough clinical history and possibly further investigations. To the rest of the population, we could recommend "only" the control of modifiable cardiovascular risk factors, early diagnosis and adequate treatment of CHD.

Even our ability to recognize future cardiac arrest in the group with known heart disease is limited. Most SCD studies concentrated on people with CHD, especially after myocardial infarction and/or HF. Based on their results, the individual's LVEF and functional capacity are central to SCD risk stratification. However, the assessment of functional capacity is subjective and can change significantly over time ${ }^{48}$. Severe left ventricular dysfunction is thus the strongest independent predictor of SCD, but risk stratification based on LVEF alone is not sufficient. It cannot identify a large subset of people without known heart disease and those with heart disease with normal or slightly reduced LVEF (Fig. 3) (ref. ${ }^{47,49,50}$ ). Especially women do not benefit from the current risk stratification. They are $50 \%$ less likely to have severe systolic dysfunction and, at the same time, they are less likely to have known heart disease before SCD (ref. ${ }^{51}$ ).

Moreover, only some patients with an implanted ICD according to the current guidelines receive appropriate ICD therapy. Of 829 patients, $31 \%$ received shocks from their device for any cause and $21 \%$ received shocks for rapid VT/VF. During five years of follow-up, the average annual rate of appropriate ICD shocks was $5.1 \%$ (ref. ${ }^{31}$ ). Around $10 \%$ of patients with ICD experience an inadequate shock with all its psychosocial consequences ${ }^{52-55}$. Avoidable ICD shocks can be reduced by evidence-based programming of the detection rate, detection duration, antitachycardia pacing, algorithms that discriminate supraventricular tachycardia from VT, and specific programming to minimize the sensing of noise ${ }^{56,57}$. ICD programming based on the current guidelines is associated with a significantly lower rate of ICD therapy and shock without changes in mortality, however only one-third of the studied population had an ICD device programmed in concordance with current guidelines ${ }^{58}$.

Several SCD risk markers have been proposed for patients with myocardial ischemia, including programmed ventricular stimulation, late potentials, heart rate variability, baroreflex sensitivity, QT interval dispersion, microvolt T-wave alternans and heart rate turbulence. Despite the promising outcomes of the early studies, none of these "predictors" has influenced clinical practice? . High expectations are placed on research of genetic markers of arrhythmic risk and magnetic resonance imaging, especially with the application of gadolinium contrast agent, which can distinguish ischemic and non-ischemic myocardial damage.

Nowadays, it seems unlikely that any single measure will have sufficient discrimination to be used in isolation. Combining known measures in a composite score or serial testing need to be evaluated. The personalized approach is exactly the goal of the PROFID project funded by the European Union (https://profid-project.eu/). It is the study for developing and validating a multivariable clinical prediction model for risk of SCD in patients with prior myocardial infarction. This model will be based on a collection of existing highly phenotyped data with the largest number of post-myocardial infarction patients ever in this regard $(\sim 1,000,000$ patients of both sexes $)$. The databases represent a wide variety of data sources such as national registries, institutional research databases, electronic health records and claims databases. The project will then compare this model against current clinical practice in patients with $\mathrm{LVEF} \leq 35 \%$ and $\mathrm{LVEF}>35 \%$ in two multinational randomised clinical trials - PROFIDReduced and PROFID-Preserved. All major stakeholders are represented: academic institutions with top expertise in SCD, European Society of Cardiology, patient organizations, large hospital chains, a large statutory health insurance company, policymakers, and state authorities across Europe ${ }^{59}$.

\section{CONCLUSION}

SCD represents a serious problem due to its incidence and impact on society, especially the victims' families. Thanks to better treatment and prevention of cardiovascular disease, cardiovascular mortality and thus the incidence of SCD has decreased. However, SCD is still responsible for more than half of all cardiovascular deaths. 
The overall rate of survival from out-of-hospital cardiac arrest remains low. This underlines the importance of primary prevention, with ICDs playing an important role in high-risk patients. Our ability to identify these patients is insufficient. Currently, the risk stratification and prevention of SCD is targeted at a preselected population with certain characteristics of heart disease. Reduced LVEF is the strongest independent predictor, but it has low sensitivity and specificity. Selected patients represent a relatively heterogeneous group with different comorbidities and prognosis. We need other predictors to help us identify subgroups which will benefit from prevention strategies. We also need to improve risk stratification in people without known heart disease as well as in those with a history of heart disease, but with normal or slightly reduced LVEF. More attention should be paid to women who have a lower risk of SCD, but are more likely to have SCD as the first sign of heart disease. They are also less likely to have severe systolic dysfunction before death and benefit from current prevention strategies. SCD is a "perfect storm" - interaction of a vulnerable substrate (genetic or acquired changes in the electrical or mechanical properties of the heart) with multiple transient factors that participate in triggering the fatal event and can change over time. The risk stratification will thus require regular reassessment. At the present time, early defibrillation is emphasized, as in the past, the most common mechanism of SCD was VT degenerating into ventricular fibrillation. In contrast to earlier data, the most common initial recording is asystole or PEA, against which our strategies are ineffective. This represents another challenge for the future.

\section{Search strategy and selection criteria}

Our research strategy was focused on the current state of knowledge about SCD. We examined studies and articles from various resources (e.g. PubMed, ResearchGate). The search terms included: sudden cardiac death, sudden cardiac death incidence, sudden cardiac death prevention, risk stratification, implantable cardioverter-defibrillator. Citations from journals with high impact factors were given special weight.

\section{ABBREVIATIONS}

ACEi, Angiotensin-converting enzyme inhibitors; ARB, Angiotensin II type I receptor blockers; ARNI, Angiotensin receptor-neprilysin inhibitor; CHD, Coronary heart disease; CPR, Cardiopulmonary resuscitation; HCM, Hypertrophic cardiomyopathy; HF, Heart failure; HFrEF, Heart failure with reduced ejection fraction; ICD, Implantable cardioverter-defibrillator; LVEF, Left ventricular ejection fraction; PEA, Pulseless electrical aktivity; SCD, Sudden cardiac death; SGLT2i, Sodium-glucose cotransporter-2 inhibitor; VT, Ventricular tachycardia; VF, Ventricular fibrillation.
Acknowledgement: Supported by Palacký University grant no. IGA_LF_2021_046.

Author contributions: JO: literature search and manuscript writing; ES, EK, MT: critical reading and manuscript revision.

Conflict of interest statement: None declared.

\section{REFERENCES}

1. Myerburg RJ, Goldberger JJ. Cardiac Arrest and Sudden Cardiac Death. In: Braunwald's Heart Disease: A Textbook of Cardiovascular Medicine. 11 th ed. Elsevier; 2018

2. Stecker EC, Reinier K, Marijon E, Narayanan K, Teodorescu C, UyEvanado A, Gunson K, Jui J, Chugh SS. Public Health Burden of Sudden Cardiac Death in the United States. Circ Arrhythm Electrophysiol 2014;7(2):212-7.

3. Paratz ED, Rowsell L, Zentner D, Parsons S, Morgan N, Thompson T, James P, Pflaumer A, Semsarian C, Smith K, Stub D, La Gerche A. Cardiac arrest and sudden cardiac death registries: a systematic review of global coverage. Open Heart 2020;7(1):e001195.

4. Goldberger JJ, Buxton AE, Cain M, Costantini O, Exner DV, Knight BP, Lloyd-Jones D, Kadish AH, Lee B, Moss A, Myerburg R, Olgin J, Passman R, Rosenbaum D, Stevenson W, Zareba W, Zipes DP. Risk Stratification for Arrhythmic Sudden Cardiac Death: Identifying the Roadblocks. Circulation 2011;123(21):2423-30.

5. Chugh SS, Jui J, Gunson K, Stecker EC, John BT, Thompson B, Ilias N, Vickers C, Dogra V, Daya M, Kron J, Zheng Z-J, Mensah G, McAnulty J. Current burden of sudden cardiac death: Multiple source surveillance versus retrospective death certificate-based review in a large U.S. community. J Am Coll Cardiol 2004;44(6):1268-75.

6. Virani SS, Alonso A, Benjamin EJ, Bittencourt MS, Callaway CW, Carson AP, Chamberlain AM, Chang AR, Cheng S, Delling FN, Djousse L, Elkind MSV, Ferguson JF, Fornage M, Khan SS, Kissela BM, Knutson KL, Kwan TW, Lackland DT, Lewis TT, Lichtman JH, Longenecker CT, Loop MS, Lutsey PL, Martin SS, Matsushita K, Moran AE, Mussolino ME, Perak AM, Rosamond WD, Roth GA, Sampson UKA, Satou GM, Schroeder EB, Shah SH, Shay CM, Spartano NL, Stokes A, Tirschwell DL, VanWagner LB, Tsao CW, On behalf of the American Heart Association Council on Epidemiology and Prevention Statistics Committee and Stroke Statistics Subcommittee. Heart Disease and Stroke Statistics-2020 Update: A Report From the American Heart Association. Circulation [Internet]. 2020 March 3 [cited 2021 Jun 8];141(9).

7. Priori SG, Blomström-Lundqvist $C$, Mazzanti A, Blom N, Borggrefe $M$, Camm J, Elliott PM, Fitzsimons D, Hatala R, Hindricks G, Kirchhof P, Kjeldsen K, Kuck K-H, Hernandez-Madrid A, Nikolaou N, Norekvål TM, Spaulding C, Van Veldhuisen DJ. 2015 ESC Guidelines for the management of patients with ventricular arrhythmias and the prevention of sudden cardiac death:The Task Force for the Management of Patients with Ventricular Arrhythmias and the Prevention of Sudden Cardiac Death of the European Society of Cardiology (ESC)Endorsed by: Association for European Paediatric and Congenital Cardiology (AEPC). Eur Heart J 2015;36(41):2793-867.

8. Eckart RE, Shry EA, Burke AP, McNear JA, Appel DA, Castillo-Rojas LM, Avedissian L, Pearse LA, Potter RN, Tremaine L, Gentlesk PJ, Huffer L, Reich SS, Stevenson WG. Sudden Death in Young Adults. J Am Coll Cardiol 2011;58(12):1254-61.

9. Adabag AS. Sudden Death After Myocardial Infarction. JAMA. 2008;300(17):2022.

10. Albert CM, Mittleman MA, Chae CU, Lee IM, Hennekens $\mathrm{CH}$, Manson JE. Triggering of sudden death from cardiac causes by vigorous exertion. N Engl J Med 2000;343(19):1355-61.

11. Jouven $X$, Desnos $M$, Guerot $C$, Ducimetière P. Predicting Sudden Death in the Population: The Paris Prospective Study I. Circulation 1999;99(15):1978-83.

12. Hookana E, Junttila MJ, Kaikkonen KS, Ukkola O, Kesäniemi YA, Kortelainen M-L, Huikuri HV. Comparison of Family History of Sudden Cardiac Death in Nonischemic and Ischemic Heart Disease. Circ Arrhythm Electrophysiol 2012;5(4):757-61.

13. Kaikkonen KS, Kortelainen M-L, Linna E, Huikuri HV. Family History and the Risk of Sudden Cardiac Death as a Manifestation of an Acute Coronary Event. Circulation 2006;114(14):1462-7. 
14. Hallstorm AP, Eisenberg MS, Bergner L. The Persistence of Ventricular Fibrillation and Its Implication for Evaluating EMS. Emerg Health Serv Q. 1983;1(4):41-9.

15. de Luna AB, Coumel P, Leclercq JF. Ambulatory sudden cardiac death Mechanisms of production of fatal arrhythmia on the basis of data from 157 cases. Am Heart J 1989;117(1):151-9.

16. Huikuri HV, Castellanos A, Myerburg RJ. Sudden Death Due to Cardiac Arrhythmias. N Engl J Med 2001;345(20):1473-82.

17. Herlitz J. Experiences from treatment of out-of-hospital cardiac arrest during 17 years in Göteborg. Eur Heart J 2000;21(15):1251-8.

18. Kuisma M, Repo J, Alaspää A. The incidence of out-of-hospital ventricular fibrillation in Helsinki, Finland, from 1994 to 1999. The Lancet 2001;358(9280):473-4.

19. Cobb LA. Changing Incidence of Out-of-Hospital Ventricular Fibrillation, 1980-2000. JAMA 2002 December 18;288(23):3008.

20. Polentini MS, Pirrallo RG, McGill W. The Changing Incidence of Ventricular Fibrillation in Milwaukee, Wisconsin (1992-2002). Prehosp Emerg Care 2006;10(1):52-60.

21. Steinberg C, Laksman ZWM, Krahn AD. Sudden cardiac death: A reappraisal. Trends Cardiovasc Med 2016;26(8):709-19.

22. Nadkarni VM. First Documented Rhythm and Clinical Outcome From In-Hospital Cardiac Arrest Among Children and Adults. JAMA 2006;295(1):50.

23. Meaney PA, Nadkarni VM, Kern KB, Indik JH, Halperin HR, Berg RA Rhythms and outcomes of adult in-hospital cardiac arrest*: Crit Care Med 2010;38(1):101-8.

24. Perkins GD, Gräsner J-T, Semeraro F, Olasveengen T, Soar J, Lott C, Van de Voorde P, Madar J, Zideman D, Mentzelopoulos S, Bossaert L, Greif R, Monsieurs K, Svavarsdóttir H, Nolan JP, Ainsworth S, Akin S, Alfonzo A, Andres J, Attard Montalto S, Barelli A, Baubin $M$, Behringer $W$, Bein $B$, Biarent $D$, Bingham R, Blom M, Boccuzzi $A$ Borra V, Bossaert L, Böttiger BW, Breckwoldt J, Brissaud O, Burkart R, Cariou A, Carli P, Carmona F, Cassan P, Castren M, Christophides T, Cimpoesu CD, Clarens C, Conaghan P, Couper K, Cronberg T, De Buck E, de Lucas N, De Roovere A, Deakin CD, Delchef J, Dirks B, Djakow J, Djarv T, Druwe P, Eldin G, Ersdal H, Friberg H, Genbrugge C, Georgiou M, Goemans E, Gonzalez-Salvado V, Gradisek P, Graesner JT, Greif R, Handley AJ, Hassager C, Haywood K, Heltne JK, Hendrickx D, Herlitz J, Hinkelbein J, Hoffmann F, Hunyadi Anticevic S, Johannesdottir GB, Khalifa G, Klaassen B, Koppl J, Kreimeier U, Kuzovlev A, Lauritsen T, Lilja G, Lippert F, Lockey A, Lott C, Lulic I, Maas M, Maconochie I, Madar J, Martinez-Mejias A, Masterson S, Mentzelopoulos SD, Meyran D, Monsieurs KG, Morley C, Moulaert VRM, Mpotos N, Nikolaou N, Nolan JP, Olasveengen TM, Oliver E, Paal P, Pellis T, Perkins GD, Pflanzl-Knizacek L, Pitches K, Poole K, Raffay V, Renier W, Ristagno G, Roehr CC, Rosell-Ortiz F, Rudiger M, Safri A, Sanchez Santos L, Sandroni C, Sari F, Scapigliati A, Schilder S, Schlieber J, Schnaubelt S, Semeraro F, Shammet S, Singletary EM, Skare C, Skrifvars MB, Smyth M, Soar J, Svavarsdottir H, Szczapa T, Taccone F, Tageldin Mustafa M, Te Pas A, Thies KC, Tjelmeland IBM, Trevisanuto D, Truhlar A, Trummer G, Turner NM, Urlesberger B, Vaahersalo J, Van de Voorde P, Van Grootven H, Wilkinson D, Wnent J, Wyllie JP, Yeung J, Zideman DA. European Resuscitation Counci Guidelines 2021: Executive summary. Resuscitation 2021;161:1-60.

25. Semeraro F, Greif R, Böttiger BW, Burkart R, Cimpoesu D, Georgiou M, Yeung J, Lippert F, S Lockey A, Olasveengen TM, Ristagno G, Schlieber J, Schnaubelt S, Scapigliati A, G Monsieurs K. European Resuscitation Council Guidelines 2021: Systems saving lives. Resuscitation 2021;161:80-97.

26. Gräsner J-T, Herlitz J, Tjelmeland IBM, Wnent J, Masterson S, Lilja G, Bein B, Böttiger BW, Rosell-Ortiz F, Nolan JP, Bossaert L, Perkins GD. European Resuscitation Council Guidelines 2021: Epidemiology of cardiac arrest in Europe. Resuscitation 2021;161:61-79.

27. Cardiac Arrhythmia Suppression Trial (CAST) Investigators. Preliminary report: effect of encainide and flecainide on mortality in a randomized trial of arrhythmia suppression after myocardia infarction. N Engl J Med 1989;321(6):406-12.

28. Cardiac Arrhythmia Suppression Trial II Investigators. Effect of the antiarrhythmic agent moricizine on survival after myocardial infarction. N Engl J Med 1992;327(4):227-33.

29. Julian D, Camm A, Frangin G, Janse M, Munoz A, Schwartz P, Simon P. Randomised trial of effect of amiodarone on mortality in patients with left-ventricular dysfunction after recent myocardial infarction: EMIAT. The Lancet 1997;349(9053):667-74.
30. Cairns JA, Connolly SJ, Roberts R, Gent M. Randomised trial of outcome after myocardial infarction in patients with frequent or repetitive ventricular premature depolarisations: CAMIAT. The Lancet 1997;349(9053):675-82.

31. Bardy GH, Lee KL, Mark DB, Poole JE, Packer DL, Boineau R, Domanski M, Troutman C, Anderson J, Johnson G, McNulty SE, ClappChanning N, Davidson-Ray LD, Fraulo ES, Fishbein DP, Luceri RM, Ip JH. Amiodarone or an Implantable Cardioverter-Defibrillator for Congestive Heart Failure. N Engl J Med 2005;352(3):225-37.

32. The Cardiac Insufficiency Bisoprolol Study II (CIBIS-II): a randomised trial. Lancet Lond Engl 1999;353(9146):9-13.

33. Effect of metoprolol CR/XL in chronic heart failure: Metoprolol CR/XL Randomised Intervention Trial in-Congestive Heart Failure (MERITHF). The Lancet 1999;353(9169):2001-7.

34. Al-Gobari M, Khatib CE, Pillon F, Gueyffier F. Beta-blockers for the prevention of sudden cardiac death in heart failure patients: a meta-analysis of randomized controlled trials. BMC Cardiovasc Disord 2013;13(1):52.

35. McDonagh TA, Metra M, Adamo M, Gardner RS, Baumbach A, Böhm M, Burri H, Butler J, Čelutkienė J, Chioncel O, Cleland JGF, Coats AJS, Crespo-Leiro MG, Farmakis D, Gilard M, Heymans S, Hoes AW, Jaarsma T, Jankowska EA, Lainscak M, Lam CSP, Lyon AR, McMurray JJV, Mebazaa A, Mindham R, Muneretto C, Francesco Piepoli M, Price S, Rosano GMC, Ruschitzka F, Kathrine Skibelund A, ESC Scientific Document Group, de Boer RA, Christian Schulze P, Abdelhamid M, Aboyans V, Adamopoulos S, Anker SD, Arbelo E, Asteggiano R, Bauersachs J, Bayes-Genis A, Borger MA, Budts W, Cikes M, Damman K, Delgado V, Dendale P, Dilaveris P, Drexel H, Ezekowitz J, Falk V, Fauchier L, Filippatos G, Fraser A, Frey N, Gale CP, Gustafsson F, Harris J, lung $B$, Janssens $S$, Jessup $M$, Konradi A, Kotecha D, Lambrinou E, Lancellotti P, Landmesser U, Leclercq C, Lewis BS, Leyva F, Linhart A, Løchen M-L, Lund LH, Mancini D, Masip J, Milicic D, Mueller C, Nef $H$, Nielsen J-C, Neubeck L, Noutsias M, Petersen SE, Sonia Petronio A, Ponikowski P, Prescott E, Rakisheva A, Richter DJ, Schlyakhto E, Seferovic P, Senni M, Sitges M, Sousa-Uva M, Tocchetti CG, Touyz RM, Tschoepe C, Waltenberger J, Adamo M, Baumbach A, Böhm M, Burri H, Čelutkienè J, Chioncel O, Cleland JGF, Coats AJS, CrespoLeiro MG, Farmakis D, Gardner RS, Gilard M, Heymans S, Hoes AW, Jaarsma T, Jankowska EA, Lainscak M, Lam CSP, Lyon AR, McMurray JJV, Mebazaa A, Mindham R, Muneretto C, Piepoli MF, Price S, Rosano GMC, Ruschitzka F, Skibelund AK. 2021 ESC Guidelines for the diagnosis and treatment of acute and chronic heart failure. Eur Heart J 2021;42(36):3599-726.

36. Ackerman MJ, Priori SG, Dubin AM, Kowey P, Linker NJ, Slotwiner D, Triedman J, Van Hare GF, Gold MR. Beta-blocker therapy for long QT syndrome and catecholaminergic polymorphic ventricular tachycardia: Are all beta-blockers equivalent? Heart Rhythm 2017;14(1):e414.

37. McMurray JJV, Packer M, Desai AS, Gong J, Lefkowitz MP, Rizkala AR, Rouleau JL, Shi VC, Solomon SD, Swedberg K, Zile MR. AngiotensinNeprilysin Inhibition versus Enalapril in Heart Failure. N Engl J Med 2014;371(11):993-1004.

38. Desai AS, McMurray JJV, Packer M, Swedberg K, Rouleau JL, Chen F, Gong J, Rizkala AR, Brahimi A, Claggett B, Finn PV, Hartley LH, Liu J, Lefkowitz M, Shi V, Zile MR, Solomon SD. Effect of the angiotensinreceptor-neprilysin inhibitor LCZ696 compared with enalapril on mode of death in heart failure patients. Eur Heart J 2015;36(30):19907.

39. Fernandes GC, Fernandes A, Cardoso R, Penalver J, Knijnik L, Mitrani RD, Myerburg RJ, Goldberger JJ. Association of SGLT2 inhibitors with arrhythmias and sudden cardiac death in patients with type 2 diabetes or heart failure: A meta-analysis of 34 randomized controlled trials. Heart Rhythm 2021;S1547527121002393.

40. A Comparison of Antiarrhythmic-Drug Therapy with Implantable Defibrillators in Patients Resuscitated from Near-Fatal Ventricular Arrhythmias. N Engl J Med 1997;337(22):1576-84.

41. Buxton $A E$, Lee $K L$, Fisher JD, Josephson ME, Prystowsky EN, Hafley G. A Randomized Study of the Prevention of Sudden Death in Patients with Coronary Artery Disease. N Engl J Med 1999;341(25):1882-90.

42. Kuck K-H, Cappato R, Siebels J, Rüppel R. Randomized Comparison of Antiarrhythmic Drug Therapy With Implantable Defibrillators in Patients Resuscitated From Cardiac Arrest: The Cardiac Arrest Study Hamburg (CASH). Circulation 2000;102(7):748-54. 
43. Connolly S. Meta-analysis of the implantable cardioverter defibrillator secondary prevention trials. Eur Heart J 2000;21(24):2071-8.

44. Moss AJ, Zareba W, Hall WJ, Klein H, Wilber DJ, Cannom DS, Daubert JP, Higgins SL, Brown MW, Andrews ML. Prophylactic Implantation of a Defibrillator in Patients with Myocardial Infarction and Reduced Ejection Fraction. N Engl J Med 2002;346(12):877-83.

45. Hohnloser SH, Kuck KH, Dorian P, Roberts RS, Hampton JR, Hatala R, Fain E, Gent M, Connolly SJ. Prophylactic Use of an Implantable Cardioverter-Defibrillator after Acute Myocardial Infarction. N Engl J Med 2004;351(24):2481-8.

46. Steinbeck G, Andresen D, Seidl K, Brachmann J, Hoffmann E, Wojciechowski D, Kornacewicz-Jach Z, Sredniawa B, Lupkovics G, Hofgärtner F, Lubinski A, Rosenqvist M, Habets A, Wegscheider K, Senges J. Defibrillator Implantation Early after Myocardial Infarction. N Engl J Med 2009;361(15):1427-36.

47. Wellens HJJ, Schwartz PJ, Lindemans FW, Buxton AE, Goldberger JJ, Hohnloser SH, Huikuri HV, Kaab S, La Rovere MT, Malik M, Myerburg RJ, Simoons ML, Swedberg K, Tijssen J, Voors AA, Wilde AA. Risk stratification for sudden cardiac death: current status and challenges for the future. Eur Heart J 2014;35(25):1642-51.

48. Raphael C, Briscoe C, Davies J, lan Whinnett Z, Manisty C, Sutton R, Mayet J, Francis DP. Limitations of the New York Heart Association functional classification system and self-reported walking distances in chronic heart failure. Heart 2007;93(4):476-82.

49. Stecker EC, Vickers C, Waltz J, Socoteanu C, John BT, Mariani R, McAnulty JH, Gunson K, Jui J, Chugh SS. Population-Based Analysis of Sudden Cardiac Death With and Without Left Ventricular Systolic Dysfunction. J Am Coll Cardiol 2006;47(6):1161-6.

50. Narayanan K, Reinier K, Uy-Evanado A, Teodorescu C, Chugh $\mathrm{H}$, Marijon E, Gunson K, Jui J, Chugh SS. Frequency and Determinants of Implantable Cardioverter Defibrillator Deployment Among Primary Prevention Candidates With Subsequent Sudden Cardiac Arrest in the Community. Circulation 2013;128(16):1733-8.

51. Chugh SS, Uy-Evanado A, Teodorescu C, Reinier K, Mariani R, Gunson K, Jui J. Women Have a Lower Prevalence of Structural Heart Disease as a Precursor to Sudden Cardiac Arrest. J Am Coll Cardiol 2009;54(22):2006-11.

52. Daubert JP, Zareba W, Cannom DS, McNitt S, Rosero SZ, Wang $P_{\text {, }}$ Schuger C, Steinberg JS, Higgins SL, Wilber DJ, Klein H, Andrews
ML, Hall WJ, Moss AJ. Inappropriate Implantable CardioverterDefibrillator Shocks in MADIT II. J Am Coll Cardiol 2008;51(14):135765.

53. Wilkoff BL, Williamson BD, Stern RS, Moore SL, Lu F, Lee SW, Birgersdotter-Green UM, Wathen MS, Van Gelder IC, Heubner BM, Brown ML, Holloman KK. Strategic Programming of Detection and Therapy Parameters in Implantable Cardioverter-Defibrillators Reduces Shocks in Primary Prevention Patients. J Am Coll Cardiol 2008;52(7):541-50.

54. van Rees JB, Borleffs CJW, de Bie MK, Stijnen T, van Erven L, Bax $J J$, Schalij MJ. Inappropriate Implantable Cardioverter-Defibrillator Shocks. J Am Coll Cardiol 2011;57(5):556-62.

55. Ruwald A-CH, Sood N, Ruwald MH, Jons C, Clyne CA, Mcnitt S, Wang $\mathrm{P}$, Zareba W, Moss AJ. Frequency of Inappropriate Therapy in Patients Implanted with Dual- Versus Single-Chamber ICD Devices in the ICD Arm of MADIT-CRT: Inappropriate Therapy in Single Versus Dual Chamber. J Cardiovasc Electrophysiol 2013;24(6):672-9.

56. Wilkoff BL, Fauchier L, Stiles MK, Morillo CA, Al-Khatib SM, Almendral J, Aguinaga L, Berger RD, Cuesta A, Daubert JP, Dubner S, Ellenbogen KA, Mark Estes NA 3rd, Fenelon G, Garcia FC, Gasparini M, Haines DE, Healey JS, Hurtwitz JL, Keegan R, Kolb C, Kuck KH, Marinskis G, Martinelli M, McGuire M, Molina LG, Okumura K, Proclemer A, Russo AM, Singh JP, Swerdlow CD, Teo WS, Uribe W, Viskin S, Wang CC, Zhang S. 2015 HRS/EHRA/APHRS/SOLAECE expert consensus statement on optimal implantable cardioverter-defibrillator programming and testing. Heart Rhythm 2016;13(2):e50-86.

57. Stiles MK, Fauchier L, Morillo CA, Wilkoff BL, ESC Scientific Document Group, Boveda S, Gold MR, Keegan R, Kutyifa V, Lau C-P, McGuire MA, Mulpuru SK, Slotwiner DJ, Uribe W. 2019 HRS/EHRA/APHRS/LAHRS focused update to 2015 expert consensus statement on optimal implantable cardioverter-defibrillator programming and testing. EP Eur 2019;21(9):1442-3.

58. Ananwattanasuk T, Tanawuttiwat T, Chokesuwattanaskul R, Lathkar-Pradhan S, Barham W, Oral H, Thakur RK, Jongnarangsin K. Programming implantable cardioverter-defibrillator in primary prevention: Guideline concordance and outcomes. Heart Rhythm 2020;17(7):1101-6.

59. Dagres N, Peek N, Leclercq C, Hindricks G. The PROFID project. Eur Heart J 2020;41(39):3781-2. 